\title{
WILL REMOTE WORKING BE THE NEW NORMAL? THE CHALLENGES FACED BY ORGANISATIONS IN FACILITATING IT
}

\author{
SAKSHI CHAUDHARY \\ Masters in Business Administration (Human Resources) \\ Symbiosis Institute of International Business- Hinjewadi, Symbiosis International (Deemed University), Pune, Maharashtra, \\ India
}

\begin{abstract}
Remote working is making it way in the future of work. Due to the COVID-19 pandemic it got a push and organisations have started accepting remote working and leveraging its advantages rather than focussing on the challenges. The paper discusses about what is remote work, what are the pros and cons. What is the general feeling regarding remote working. The paper also discusses the major challenges faced and some strategies on how management can minimise it. It discusses how management can make it easier for employees so that productivity is not compromised in any way. The future is unknown and therefore organisations must start developing strategies and policies to accommodate any kind of changes. The organisations must be quick to adapt. Remote working is not a new concept, the acceptance rate for it is low even though there are statistics and data available that prove it to be beneficial for both the employees and the business.

KEYWORDS: Remote working, Pandemic, COVID_19 \& Employee management
\end{abstract}

Received: Jun 08, 2020; Accepted: Jun 28, 2020; Published: Sep 10, 2020; Paper Id.: IJMPERDJUN20201149

\section{INTRODUCTION}

Amidst the ongoing pandemic, one question that very prominently strikes up is how much percentage of the workforce is willing to go back to work on the first day after the end of the crisis. Why so much hesitance? Covid19 is a deadly disease caused by the Coronavirus that is making us avoid all kinds of human touch and people are instructed to maintain physical distance for safety and precautionary measures. This emergency has forced countries to go on lockdown and left companies only with one option to continue working and that is work from home.

Telecommuting, Remote working, work from home, etc, are the few buzzwords that we are continuously hearing today in this pandemic situation of Coronavirus. One might wonder why? Countries are going into lockdown for several months and everyone is advised to stay in isolation till the condition normalizes so how do companies get their work done. Here is where remote working steps in and helps the world to carry on with their jobs enabling them to run the companies from the comfort of their homes.

Remote working is not a new concept, the acceptance rate for it is low even though there are statistics and data available that prove it to be beneficial for both the employees and the business. A remarkable increase of $173 \%$ was seen in the remote working space since 2003. Employees preferred telecommuting due to multiple reasons such as; time saved due to no traveling, less distractions and no complications with office politics. A study in 2014 by PGi suggested that $61 \%$ of business owners that company profits increased because of remote workers, $83 \%$ of entrepreneurs felt employee productivity accelerated due to flexible hours. $82 \%$ of remote employees had low-stress levels, $51 \%$ admitted to spending more time with loved ones, $48 \%$ reported better sleep cycle, all of it contributing to satisfaction of employees in their work and personal life. Better life satisfaction leads to higher productivity and 
efficiency which in turn helps businesses to get their targeted results.

One department that has faced the most challenges and has come up on the front line is the Human Resources department which is the manager of workforce. The Human Resources department had a major role to play in helping the employees go remote and make the running of the business smooth. They had no shortage of difficult decisions lying ahead of them. The department overall saw a collaborative effort rather than the functional which is the normal routine.

All departments of various HR functions combined as one to make work from home easier and beneficial for both the employer and the employees. This was not an easy task as there were many difficulties such as communication, technology enabling, employee engagement to name a few. All the functions were taken online and had to be managed virtually from recruitment to onboarding to layoffs. Maintaining the employee's emotional and physical wellbeing came across as a major concern as people can be stressed and feel demotivated very easily in such times.

The paper will also analyse the employee's perspective of the changes and actions taken by the HR department. What is the employee's opinion and are they comfortable with the new work setting? Are they willing to work remotely for the long term? What were the problems they faced in regards to the HR's requirements and instructions? This will help us to give a holistic understanding of the situation and the primary question of the research paper that is will Remote working be the new normal and what are the challenges faced by HR in facilitating it.

With remote working being introduced all around the world and the necessity of the same increasing every day the question is that is remote working here to stay. Will it be the new norm, will companies readily accept the change, are the companies equipped to follow suit, and many more unanswered questions arise due to the unprecedented event. Well, all of it is very subjective to the type of company, workforce size, location, and other characteristics. All of what will be done going forward will be keeping in mind the people and their wellbeing.

\section{LITERATURE REVIEW}

It is not hidden that the human resources department became the frontline disaster management team during this crisis for all organisations. We can completely agree with Boston Consulting Group's statement that this pandemic is a "people's crisis" as we can see that a number of strategic human talent concerns have risen up. This might be a first for many managers in managing remote teams.

The review aims to understand remote working, various aspects of it and the current scenario. The review also aims at finding out whether such challenges were identified earlier. The review is going to talk about papers in the recent past that is last 10 years as we need to know the growth in acceptance rate of remote working. Understanding it has become imperative now since the pandemic is leading us to a new normal where we may not have to commute to our offices every day. Getting a deeper knowledge about it will help us understand the problems and challenges it will bring with itself. With the help of this research we can then come out with solutions and ideas on how to tackle them and be prepared next time such crisis hits us.

$23 \%$ of the employees who were participants to a survey by Aliah D. Wright preferred to work for longer durations and $42 \%$ of the remote employees are just as much in contact with the employees as they are while working onsite. Eileen O'Laughlin (2020) suggests that organisations that support remote working must create a community mindset with automatic check-ins, regularly checking on each employee and trying to know more about their personal well- 
beingand have bonding activities so they don't feel isolated. A survey by Capterra (2019) concluded that 92\% of respondents had faith in their company to perform remotely with the help of the technology already in place with their respective organisations to collaborate and communicate.

Numerous researches have brought light to the fact that HR practices are crucial for a firm's success. For years to come remote work will be looked from a strategic view. HR managers will have to broaden their minds in accepting remote work and gauge its necessity. If the managers can successfully restructure and design various processes for an organisation such as communication, delegation, coordination then only will it be effective. Becoming the master of team management is the primary focus in the current scenario and the strategy will be to work in flexible groups in different locations. Remote team management will be important and the managers will have to make sure that it is conveyed to the employees that each one of them is welcome to speak up. (Gerdeman Dina, 2020)

To overcome challenges, HR managers are advised to encourage their employees to take advantage of technology provided by the company or to stay in contact with colleagues and supervisors personally. Staying connected will help avoid the feeling of isolation that many employees may suffer from. One can use company provided technology or social media like LinkedIn, Instagram, etc, whatever is best suitable. (Dan Shewan, 2017)

It's not just the managers that are having trouble in making the in-office employees remote, even the already existing remote workforce is faced with challenges as now remote working is staying at home only. With all the nonessential businesses shut down for the time being, the remote workers are unable to locate alternative workspaces such as libraries, coffee shops, and other co- working spaces available. This has limited the segmentation of work and personal space which makes it difficult for employees to switch off after working hours. (Chawla, MacGowan, Gabriel, \&Podsakoff, 2020)

The literature review suggests that it is the human resources department that plays a major role in facilitation of remote work. During this pandemic the importance of remote work has risen and so the role of HR. The literature exists for the effects and impact of remote working on the worker and their performance but not much stress has been put on the role of human resources manager. Since this pandemic is a first for everyone not much literature exists on what problems do HR managers face. The managers face a lot of challenges and difficulties during this period. This paper attempt to look at those challenges and how the HR leaders have routed their way through this crisis and came out stronger and at identifying any kind of opportunities that a company could exploit. The paper also tries an attempt at gauging the acceptance of remote work and how the perspectives have changed and whether remote working will be the new normal.

\section{DATA FINDINGS}

Study was done on the existing research papers available in the remote working space to understand the concepts and the details about it. Advantages, disadvantages and what was the earlier trends were acknowledged through the research.

A survey was conducted to capture the general notion of remote working. The survey analysed how people felt about working remotely in the current scenario, are they willing to continue working like this and do they feel that it will be the new normal.

250 people participated in the survey working in various organisations. Out of them only $35.6 \%$ had previously experienced work from home. Majority of them had established a work routine for themselves and believed they had a healthy work and life balance. $39 \%$ felt they were equally productive, $21 \%$ participants felt they were more productive 
while the remaining found no difference in their productivity. When asked whether they enjoyed work from home only $28 \%$ responded while the rest were not sure or were happy. For the people who enjoyed work from home there were still $18 \%$ who did not want to continue it and $33 \%$ was not sure. For those who did not enjoy work from home only $1 \%$ wanted to continue working like this for obvious reasons. So, the survey then explored the reasons and issues they had while working from home. There were 3 major issues that stood out which will be later discussed in the paper.

\section{REMOTE WORKING}

Remote working is an arrangement between the employer and the employee where the employee need not necessarily come to the office premises to work. The employee may work from his home or some other workplace station kind of setting. Remote working has seen an upward growth in the last few years but remained a minority in the workforce. Due to the dreadful crisis that the world is going through the tables have turned and the remote working employees have not only become the majority but also at many companies the only workforce. Although work from home arrangement is an enabler in theses unprecedented times it comes with its problems and challenges.

\section{PROS AND CONS}

Traditional work revolves around the idea that the work is tied to a specific location. It is gathering all employees in one centralised location which permits employers to easily coordinate and manage tasks and activities with a strong internal communication. It is easier for employees as well to report, have a social connection with colleagues, consulting with seniors, etc. Contrast to that is remote working where you can work from any location which enables employees to manage their work life and personal life accordingly and there is higher job satisfaction.

Is this a win-win situation for both employees and the business? Every coin has two sides, it cannot be all on the bright side. While there is majority giving better results there is a small group of people who fall victim to loneliness, distractions at home, not being able to communicate, cannot separate the work life from personal life, overworking, etc. Until now these problems were not a major concern because remote work was not widely used. But now because of the crisis, the scenario has boosted up and the future of work looks very different from what it was a few months earlier.

It is difficult for the business as they cannot duplicate every system of traditional work and incorporate it in the virtual workspace. The major problem occurs in building and maintain the organisational culture with the remote employees. Since they are not in physical contact and do not experience the culture physically but only virtually, only some parts of the culture get recognised. Another major concern for organisations is data security and less control over employees. Even for some employees it becomes tedious to work remotely as some fall prey to social isolation, others feel that they get lesser chances at growth and advancement and some feel out of sync with the organisation.

On the other hand, there are technologies that help with communicating and extend a substitute to face to face communications like social networking sites that assist in building bridges to a few gaps. There are other advancements that help tracking progress remotely. Employees also prefer this option as they do not have to spend time travelling and can utilise that time for family or for being more productive at work. This leads to higher job satisfaction, lower turnover, motivated employees which further translates into high productivity, decrease in real estate costs for the organisation.

A number of companies had already adopted to remote working practices and owing to the Covid-19 pandemic even more organisations have become adaptable and flexible towards it. IBM is one of the top companies that already has 
work from home. Previous researches have shown that all companies react differently and adapt different ways of the remote work scenario.

\section{CHALLENGES FACED BY ORGANISATIONS}

The paper will now explore the various challenges faced by the organisations in managing employee problems. The challenges listed below are the result secondary research of various databases and short interviews of HR managers to understand their perspective on real time basis. It will also try to look at strategies and options that companies can adopt to try and resolve the issues.

1) Work-Life Balance:One major reason that people are attracted to this option is that it gives them an opportunity to maintain their work-life balance and handle all demands of both family life and work life. But that sometimes creates more problems and has a contrasting effect. Finding the right balance is tough as it becomes difficult to separate both if you are living where you are working. The demands from work and personal life are hardly compatible with each other. Not being able to successfully integrate it will affect all the stakeholders involved.

Employees often found it difficult to switch off from work, checking mails before going to sleep were becoming a habit, working on weekends, holidays and not being able to help in household chores while being there at home was creating distress amongst family members. Remote workers noticed that they were working for more hours than what they would do in traditional work which was totally opposite the motive for their choice of remote working. They felt over worked but this kind of commitment paid well for the employers in terms of short-term productivity. Not being able to segment their work-life would lead to attrition in the long term. The remote employees may also feel the need to over compensate since they are not physically present and the visibility is less. There might be an urge to prove themselves by being available all the time and taking up extra projects and putting in longer hours. Communication can also be a major issue as the volume of communication increases in remote working but there are a lot of non-verbal cues that cannot be followed up in virtual communication.

Some of the major issues for organisations: Maintaining an organised work culture, making an arrangement of flexible working, maintaining systems that allow flexible working to function smoothly, ensuring that the company is equipped with the right kind of technology, the internet facility being appropriate.

For managers: Ensuring that employees are not misusing the flexible working arrangement, giving reasonable attention to every request, not being biased, understanding the employees and their pain points, making sure employees are not overworked.

For employees: Communicating with the managers, building trust, utilizing the flexible work time ethically and only for work purpose, being productive and efficient, Not taking up unfair means and lying to get flexible working.

STRATEGY- In order to fully take advantage of the remote work setting and use its potential to benefit all parties the organisation must set some working norms and assist employees to balance their work and personal life. Employers can do so by discussing good practices of building work-life balance. The management will need to formulate the plans and communicate it to the employees and also practice it themselves. It could be not signing in on their work emails on weekends and holidays, signing out at a specific time to not receive any work mails and they themselves not sending any work-related communication after hours. Managers must prioritize the work and give constant feedback on the same. It will help employees to understand the urgency and plan their day accordingly. Communication should be proper and ample 
time must be given as time management and multitasking become a crucial aspect in remote work setting.

Work life and Non-Work life should complement each other rather than creating interference in the otherdomain. It becomes difficult to manage when stress from one side starts affecting the performance, productivity on the other side.

2) Workplace Isolation:Another major challenge while dealing with remote employees is managing workplace isolation ad its impact. Employees who suffer this have lower job satisfaction and morale which leads to high turnover for the company. Workplace isolation is common in employees who live alone or have recently joined the organisation. It is a feeling where you don't know who to turn to in order to seek advice, feel disconnected with their colleagues and not being able to contact people easily. These arise generally due to the feeling that there is no support from seniors and colleagues. Such feelings get amplified as there as fewer chances to socially interact with office people. Employees miss the informal gatherings, chats, breaks, and networking opportunities in building up personal connections. The feeling of isolation is closely attached to the actions taken up by the managers.

STRATEGY - Employees rely on managers a lot more in remote work settings to create a sense of belongingness and look up to managers for all kinds of problem solving. To overcome workplace isolation the managers must be in constant contact with the team, have one-to-one meetings, informal calls just to check up on the person. Trying to understand the issues regarding the arrangements and showing their support by being available to the employee will inculcate a feeling of commitment towards the organisation. Manager can encourage weekly informal meets amongst team members. Various activities can be conducted such as fun Fridays, sharing childhood pictures, exchanging fun stories, playing online games, etc. Birthdays, festivals and other important days can be celebrated virtually. Such activities will foster a feeling of belongingness and will also help with team building. This way the employees feel get the vibe of the organisations culture and motivated to work in virtual teams. Social interactions are very important to get the sense of working together and staying connected.

Other initiatives that managers can take are pairing new remote employees with existing employees who have experience in remote working. The old employees and guide and mentor the new employees and help them tackle with the challenges. They can share their experience on how they started out and carried on things so that the new employees do not repeat the same mistakes. Extra efforts must be taken for new employees as it will be difficult to connect virtually and know the organisation well. Management can include a list of members and their details along with photos in the welcoming package sent to employees during onboarding. It will help new employees to familiarise with the organisation and its people.

3) Communication: All the challenges are interlinked with each other. Electronic communication is the primary form of communication used for virtual setting which leads to people feeling isolated. Electronic communications such as e-mail, text messages, conference calls, etc, lack personal touch and features of face to face communication.All these become roadblocks for employees in building relationship and trust. Employees have a common complaint that decision making is delayed as communication takes much longer than actually required due to missing non verbal cues. The volume is high but there is lack of efficiency in the communications.

Apart from face-to-face communication other issue that arises are network issues due to which smooth communication is not possible. There will be people with bandwidth problems, gadget issues, etc. There are also distractions from families during calls. 
STRATEGY- Managers must try and encourage the use of video calls at all times possible. Managers can set up fixed timings for discussions and keep in constant contact while providing regular feedback. The manager also must be available throughout the working hours' time. Apart from this the management must ensure that remote workers are provided with the right kind of facilities for effective communication. They can be provided with laptops, routers, internet connection, etc or any other tech gadget that will support the communication process. Also, if possible face-to-face meetings can be scheduled in small teams while confirming to all social distancing norms.

Management can also encourage employees to make a workstation at home with providing the infrastructure to avoid distractions during calls. In case of any distraction the managers and employees must be empathetic and understand the situation and not reprimand the employee under consideration.

\section{LIMITATIONS}

While collecting information one of the few limitations that I found was not many proved methods of a successful remote working environment were available. Remote working has not been an area that is researched upon a lot. Also, while collecting the data a common misunderstanding for the participants was that they took flexible working and the work from home scenario we are in right now as similar.

There is lack of enough previous research on this topic. Since the world is still going through the pandemic and everyone is just trying and applying new ways to cope up with the challenges there is no perfect potion available. Early research has also shown that all organisations adapt to changes differently so the applicability of the strategies are very subjective.

\section{CONCLUSIONS}

Companies must develop and formulate best practices to be followed. Addressing of the challenges brought by remote working is imperative and trainings must be provided to employees to cope up with these issues. The training must cover all the employees new or old, experienced or unexperienced so that there is uniformity in the actions. The organisations must quickly adapt to the new technological advancement and leverage it to use to their benefit.

Remote working can be the new normal once all the challenges are sorted out as it has many advantages and the results show that people are expecting this to be the future. Even though people are facing issues with the work from home scenario they want to continue this remote work as it provides them with more flexibility and safety has become a major concern.

Organisation will have to adapt to this and alter their policies to accommodate remote working. Research has also proven that organisations are saving a lot more with this setting while it is difficult to manage. So, they will have to come up with new ways of managing employees and the business optimally. The best way is to take advantage of technology.

The long-term impact of the coronavirus pandemic is still uncertain so we can positively assume that the impact will not be short lived. The health experts have warned that the effects of COVID-19 will not be over so soon, but the gate to future health crisis has been opened up. Therefore, the social distancing norms can become a part of our lives and the organisations will have to adapt accordingly while giving more focus on employee well-being. 


\section{REFERENCES}

1. Joel B. Carnevalea, Isabella Hatak. 2020. Employee adjustment and well-being in the era of COVID-19: Implications for human resource management. Journal of Business Research

2. Paula Caligiuriet a. 2020. International HRM insights for navigating the COVID-19 pandemic: Implications for future research and practice. Journal of International Business Studies

3. Gerdeman Dina (2020). "How the Coronavirus is Already Rewriting the Future of Business", Harvard Business School Working Knowledge

4. O'Laughlin, E. (2020). A project manager's guide to leading remote teams. Capterra.

5. Maurer, R. (2020). Job interviews go virtual in response to COVID-19. Society for Human Resources Management

6. Michal Birona, Helen De Cieri. 2020. Structuring for innovative responses to human resource challenges. Human Resource Management Review

7. Towers-Clark, C. (2020, March 27). Will Remote Work Become the New Normal? Forbes. https://www.forbes.com/sites/charlestowersclark/2020/03/27/will-remote-work-become-the-new-normal/\#17f82d79cd1

8. Time Doctor. (2020, July 29). 9 Research-Based Facts That Prove Remote Teams are The Future of Work. https://www.timedoctor.com/blog/remote-teams-future-of-work/

9. Faragher, J. (2020, March 24). Working from home: How HR can deal with the daily dilemmas. Personnel Today. https://www.personneltoday.com/hr/remote-working-how-hr-can-deal-with-the-daily-dilemmas/

10. A Guide to Managing Your (Newly) Remote Workers. (2020, August 14). Harvard Business Review. https://hbr.org/2020/03/aguide-to-managing-your-newly-remote-workers

11. Wiles, J. (2020, May 28). 10 Questions for an HR Pandemic Plan. Smarter with Gartner. https://www.gartner.com/smarterwithgartner/10-questions-for-an-hr-pandemic-plan/

12. Meister, J. (2020, April 1). The Impact of The Coronavirus on HR and The New Normal Of Work.Forbes. https://www.forbes.com/sites/jeannemeister/2020/03/31/the-impact-of-the-coronavirus-on-hr-and-the-new-normal-ofwork/\#117ed9f32b60

13. The New Rules for Remote Work: Pandemic Edition. (2020, March 30). HBS Working Knowledge. https://hbswk.hbs.edu/item/the-new-rules-for-remote-work-pandemic-edition

14. Practical HR Resources for COVID-19 Pandemic Planning | Talent Management Blog | Saba Software. (2019). Saba. https://www.saba.com/uk/blog/practical-hr-resources-for-covid-19-pandemic-planning

15. MandeepKaur and Dr. S. Ramachandran. 2019. Manoeuvring role of hr in the age of disruption. International Journal of Advance and Innovative Research

16. State of Remote Work 2019. (2019). Buffer. https://buffer.com/state-of-remote-work-2019

17. Adamovic, M. 2018. An employee-focused human resource management perspective for the management of global virtual teams. The International Journal of Human Resource Management.

18. Zimmermann, A. 2018. Managing virtual talent. In D. G. Collings, H. Scullion, \& P. M. Caligiuri (Eds.), Global talent management

19. Peek, S. (2018b, December 27). Communication Technology and Inclusion Will Shape the Future of Remote Work. Business 
News Daily. https://www.businessnewsdaily.com/8156-future-of-remote-work.html

20. Alan Felstead and GoloHenseke. 2017. Assessing the growth of remote working and its consequences for effort, well-being and work-life balance. New Technology, Work and Employment

21. Shewan, D. (2017). 7 things nobody tells you about working remotely. WordStream.

22. Dharma RajuBathini and George Kandathil. 2015. Work from Home: A Boon or a Bane? The Missing Piece of Employee Cost. Indian Journal of Industrial Relations

23. Malhotra, A., \&Majchrzak, A. 2014. Enhancing performance of geographically distributed teams through targeted use of information and communication technologies. Human Relations

24. Martin, B. H., \& MacDonnell, R. (2012). Is telework effective for organizations? A meta-analysis of empirical research on perceptions of telework and organizational outcomes. Management Research Review

25. Lautsch, B. A., \&Kossek, E. E. (2011). Managing a blended workforce: Telecommuters and non-telecommuters. Organizational Dynamics

26. Zimmermann, A. 2011. Interpersonal relationships in transnational, virtual teams - towards a configurational perspective. International Journal of Management Reviews

27. Kelliher, C. \& Anderson, D. (2010), "Doing More with Less? Flexible Working Practices and the Intensification of Work", Human Relation

28. J.P. Mulki, W.B. Locander, G.W. Marshall, E.G. Harris and J. Hensel, 2008. "Workplace Isolation, Salesperson Commitment and Job Performance," Journal of Personal Selling \& Sales Management

29. Siha, S. M., \& Monroe, R. W. (2006). Telecommuting's past and future: A literature review and research agenda. Business Process Management Journal

30. Peters, P., \& den Dulk, L. (2003). Cross cultural differences in managers' support for homebased telework a theoretical elaboration. International Journal of Cross-Cultural Management,

31. d D.E. Bailey and N.B. Kurland, 2002. "A Review of Telework Research: Findings, New Directions and Lessons for the Study of Modern Work,” Journal of Organizational Behaviour 

